Article

\title{
Numerical Simulation of the Effect of Fire Intensity on Wind Driven Surface Fire and Its Impact on an Idealized Building
}

\author{
Ali Edalati-nejad ${ }^{1}$, Maryam Ghodrat ${ }^{2, *(\mathbb{D}}$, Sayyed Aboozar Fanaee ${ }^{1}(\mathbb{C})$ and Albert Simeoni ${ }^{3}$ \\ 1 Department of Mechanical Engineering, University of Birjand, Birjand 97175615, Iran; \\ ali.edalati@birjand.ac.ir (A.E.-n.); sab.famech@birjand.ac.ir (S.A.F.) \\ 2 School of Engineering and Information Technology, University of New South Wales Canberra, \\ Canberra, ACT 2610, Australia \\ 3 Department of Fire Protection Engineering, Worcester Polytechnic Institute, Worcester, MA 01609, USA; \\ asimeoni@wpi.edu \\ * Correspondence: m.ghodrat@unsw.edu.au
}

check for updates

Citation: Edalati-nejad, A.; Ghodrat, M.; Fanaee, S.A.; Simeoni, A. Numerical Simulation of the Effect of Fire Intensity on Wind Driven Surface Fire and Its Impact on an Idealized Building. Fire 2022, 5, 17. https://doi.org/10.3390/fire5010017

Academic Editor: Faraz Hedayati

Received: 30 November 2021

Accepted: 25 January 2022

Published: 27 January 2022

Publisher's Note: MDPI stays neutral with regard to jurisdictional claims in published maps and institutional affiliations.

Copyright: (C) 2022 by the authors. Licensee MDPI, Basel, Switzerland. This article is an open access article distributed under the terms and conditions of the Creative Commons Attribution (CC BY) license (https:// creativecommons.org/licenses/by/ $4.0 /)$.

\begin{abstract}
This paper presents an investigation on the effect of fire intensity of a wind driven surface fire, similar to a large wildfire, on an idealized structure located downstream from the fire source. A numerical simulation was conducted using an open source CFD code called FireFOAM, which is a transient solver for fire simulation and turbulent diffusion flames, supported by a large eddy simulation (LES) solver for incompressible flow. The numerical data were verified using the aerodynamic experimental data of a full-scale building model with no fire effects. An idealized cubic obstacle representing a simplified building with the dimension of $6 \times 6 \times 6 \mathrm{~m}$; is considered downstream from the fire source. Different fire intensity values of the fire line representing different grassland fuels were simulated to analyse the impact of wind-fire interaction on a built area. To solve the problem, a coupled velocity and pressure method was applied through a PIMPLE scheme in FireFoam solver of OpenFoam platform. There is a good agreement between simulated results and experimental measurements with a maximum error of $18 \%$, which confirms the validity and accuracy of the model. The results showed that by increasing the fire intensity; the velocity of the crosswind stream increases, which causes low-density air and generates an extra stream behind the fire plume. It was also found that increasing fire intensity from $10 \mathrm{MW} / \mathrm{m}$ to $18 \mathrm{MW} / \mathrm{m}$ raises the integrated temperature on the ground near the building and on the surface of the building by $26 \%$, and $69 \%$, respectively.
\end{abstract}

Keywords: wildfire; LES; wildland-urban interface; wind-fire interaction; fire intensity; wind-structure

\section{Introduction}

Although the wildland-urban interface (WUI) is not a new matter, fires in WUI communities have suddenly increased in frequency [1]. The impacts of growing wildfire have been recorded over the past few decades $[2,3]$ and are expected to increase in intensity due to climate change in different parts of the world.

Wildfire management at the wildland-urban interface (WUI) is becoming more challenging due to expanding development of human inhabitation and sharp growth of land use. This creates substantial wildfire risk to households located at these areas, as combustible grasslands are susceptible to encounter infrastructure. This condition increases the impact of wildfires on structures, especially with fast moving wildfires which makes devising the action plans more difficult.

The key point in understanding the problem and finding an appropriate solution is to deal with the aerodynamic behaviour of the flow around the built area, the rate of spread of the fire and its relation to fuel which is directly linked with the intensity of the fire. All such parameters, more or less, play a role in alleviating the impacts of wind driven wildfires on the wildland-urban interface secretions. 
Depending on the exposure conditions, structures may ignite as wildfire spreads toward a WUI community [4]. Accordingly, understanding the wind effect on the wildlandurban interface is an important criterion in predicting fire behaviour. By far, there are no experimental studies investigating the combined effect of fire and wind on structures. However, some researchers such as Richards et al. [5] have reported an experimental and numerical investigation on the mean pressure of a cube-shaped building to obtain important sets of information about the aerodynamic behaviour of a building in the wind flow without the presence of fire. Hostikka et al. [6] investigated the fire behaviour at the wildland-urban interface, focusing on the numerical simulation, and shed a light on understanding the thermal impact of bushfires on buildings. Their findings indicate that a mesh size of $0.25 \mathrm{~m}$ is appropriate for thermal radiation numerical simulations. The authors found that mirror boundaries in the computational domain on the sides of the fire front are practical and valid for decreasing the computational cost. Fryanova and Perminov [7] studied the impact of fire intensity and wind speed on the ignition probability of building structures. In the study, the crown fire is found as a heat source which was measured by the empirical data of gas velocity and mean crown fire temperature, dependent on fire intensity values. The thermal and hydrodynamic effects of wind flow on buildings were explored. The effect of fire-wind interaction on structures was investigated by Ghodrat et al. [8]. In this study, wind direction, terrain slope angle, and the impact of wind on fire modelling, were analysed. Additionally, the impact of the transmission of a fire from a wildfire to a wildland-urban interface (WUI) is explored. The authors claimed that at the wildland-urban interface (WUI), both fuels of structure and wildland can be combined, and simulations of this regime must consider the coupling effects between structural and wildland fuels. The wind and buoyancy force effects on the fire intensity were highlighted by Frangieh et al. [9]. In the study, a three-dimensional structure of a fire was investigated numerically on laboratory and field scales. In the study, the unsteady RANS approach and a Large Eddy Simulation were applied to simulate the reactive turbulent flow.

Mell et al. [10] studied the wildland-urban interface phenomenon and their challenges and reported that fire behaviour can be predicted in a near realistically broad range by physics-based models under a variety of atmospheric and terrain slope conditions. These models with supporting experimental data proved to be very useful in developing risk assessment and mitigation strategies for realistic wildland-urban interface (WUI) fuels and environmental conditions.

Ambient wind conditions also play a major role in fire spread, fire intensity and flame features [11]. Clark et al. [12] assessed the interactions between prevalent fire behaviour and fire intensity, canopy fuels, and above-canopy turbulence and energy fluxes. They investigated the fire behaviour and consumption of the fuel in wildfires linked to turbulence and energy fluxes and found that higher-intensity head fires lead to larger consumption of shrubs and canopy fuels, but they are also estimated a large increase in the turbulence and heat flux above the canopy.

Edalati-nejad et al. [13], investigated the effect of wind and terrain slope on fire and their impact on structures. In the study, a time-related simulation was performed to investigate the effect of wind-driven fire on a structure placed on inclined terrain. Various upslope terrain angles of $0,10,20$, and $30^{\circ}$ at different velocities of wind were simulated by FireFoam, a solver of OpenFOAM software. The result showed that at a constant heat release rate and wind velocity, increasing the terrain slope leads to raise in the higher temperature areas near the building. The experimental studies including empirical fires and employed fuels were reported in detail by Ghodrat et al. [14]. In their work, the latest data are reviewed, and prospective pathways are provided. An investigation on the wind flow and fire spread dynamics in a sloped terrain was performed by Abouali et al. [15]. In the work, both computational and experimental studies were conducted. The authors acknowledged that wind, fuel and terrain topography are the dominant factors affecting wildfire behaviour, in which their physical interactions cause unexpected fire behavior. The influence of fuel, weather and fire shape on fire-spread in grasslands was studied by 
Cheney et al. [16]. In the study, it was concluded that even though wind is important for grass fires, fuel load is the primary determinant of fire intensity. A numerical study and empirical measurement of flame geometry and potential of crown fire initiation in wildfire propagation was conducted by Morvan [17]. The author reported a generalized ignition of the canopy, resulting in a substantial growth of fire intensity by radiation heat transfer between the flame and the canopy as a fuel. It is also shown that the most efficient way to reduce intensity of surface fire and hence reducing the risk of converting surface fire to crown fire is to decrease fire intensity. This can be achieved by cutting off the surface biomass piled up on the ground partially or completely.

An improvement in wildfire modelling was conducted by El Houssami et al. [18]. In the investigation, an experimental and numerical study was conducted to analyse the performance of different sub-models and constraints to describe the flaming dynamics of wildfires. Their results showed a good agreement between the predicted mass loss rates and heat release rates for the used sub-model.

It is widely known that wind, fuel moisture content, fuel load, and terrain slope are the key factors influencing the behaviour of wildfires. The level of impact of a wildfire on the environment largely depends on the intensity with which the fire burns [19]. Wildfire intensity is defined by three key parameters: the weather conditions (current and forebear), the topography of the area, and the fuel load and type $[16,20]$. Particularly, once other influences such as fuel moisture are equivalent, a larger amount of fuel leads to greater fire intensity [21]. Therefore, fuel load management is a key component in wildfire alleviation practice [22].

Fuel moisture content (FMC) is a central element influencing the intensity of a fire [23], as it regulates the terms of ignition, the amount of fuel burned and the combustion rates of various categories of fuel [24]. By increasing the fuel moisture content, the fire intensity decreases; this can be explained by the massive release of water vapor ahead of the fire that effectively results in a reduction in oxygen supply to the fire-front [24], also changing the phase of the water, so the vapor needs a huge amount of heat load due to its high value of specific vaporization heat. The effect of fire intensity on live fuel fire was investigated by Trollope and Tainton [25]. The results indicate that fire intensities more than $3.5 \mathrm{MW} / \mathrm{m}$ cannot be controlled. Morvan [23] used a 2D physics-based FIRESTAR2D model to explore the behaviour of surface fire spread and to find out how moisture content of the fuel, which is directly associated with the intensity of the fire, can affect this behaviour. He proposed an exponential correlation for fire RoS that has been normalized by RoS (at $0 \%$ moisture content). Other researchers such as Overholt et al. [26] tried to characterize fuel properties of little bluestem grass experimentally. They then conducted a physics-based simulation using WFDS to investigate grassfire spread on the field scale with no grid convergence study and found a specific range of radiative heat flux associated with fuel moisture, ranging from 6 to $22 \%$; this was not similar to the high values used in $[23,24,27,28]$. The results of the study conducted by Overholt et al. [26] also showed that the fuel moisture content had the most significant impact on the fire spread rate.

Marino et al. combined experimental and physics-based modelling analysis to analyse the impact of fuel moisture content on the Rate of Spread (RoS) of a fire. (3D) FIRETEC simulations were employed for physics-based modelling. They found there is a link between moisture content, fire intensity, and fire behaviour including RoS.

Many studies have outlined the impact of FMC and, hence, fire intensity on fire behaviour. Banerjee et al. [29] also investigated the effect of fuel moisture on wildfire. Six sets of simulations representing a wide range of fire behaviour, in terms of intensity and spread rate were studied. Their findings also showed that fire intensity is significantly affected by fuel load and the speed of fire propagation, and it is influenced by wind. However, fuel moisture significantly reduces both fire intensity and rate of spread. Effect of moisture content on thermal decomposition and auto-ignition of wood, as a biofuel, was explored by Gong et al. [20]. They used FireFOAM to replicate experimental measurements. Their results showed that the temperatures increase more quickly by increasing heat flux 
and decreasing moisture content. Advection and the self-heating of organic porous media were investigated by Aganetti et al. [30]. The authors developed a convection-diffusion model using the CFD tool OpenFOAM to examine the impact of advection in the selfheating process of bio-solids. Moinuddin et al. [31] conducted a numerical study on the impact of fuel moisture on grassfire spread behaviour. Different relative humidity and fuel moisture were found to have a considerable impact on grassfire spread rate and fire intensity. Their results also showed that lower relative humidity and fuel moisture result in greater fire intensity and a faster spread.

The ignition of live fuel, using ForestFireFOAM, a CFD solver specialized to simulation of vegetation fire, based on FireFOAM, was investigated by Lamorlette et al. [32]. The authors concluded that the improved non-equilibrium thermal model can successfully calculate ignition and flaming time, peak heat release rate (HRR) at ignition and mean HRR through flaming combustion on a validation case. They found that the aforementioned parameters agree well with the obtained experimental correlations on ignition time and peak heat release rate on a wide range of fuel moisture content.

In another study, the fire spread originated from the fuel bed to the lower canopy of patterned grassland used in wildland-urban interfaces, was simulated by Terrei et al. [33]. The authors claimed that a wildland-urban interface fire starts usually in surface fuel with dead grass, then spreads to shrubs and trees when the lower canopy is near the ground. The impacts of weather condition on fire intensity and rate of fire spread were analysed in other studies [34-36].

The presented literature survey indicates that despite a number of studies carried out in the field of fire intensity and fuel content, the basic understanding of the impact of a wind-driven surface fire and its intensity on building structures in the wildland-urban interface needs more investigation.

Previous works provide indispensable data concerning the impact of fuel energy content on fire behaviour and propagation. However, the fundamental mechanisms of how the intensity of the wind driven surface fire influences the buildings at the Wildland urban interface (WUI) and how this varies temperature and wind velocity profiles on and around the building still requires further study. This work aims to fill the gap by providing a quantitative and systematic analysis of the factors contributing to the alteration of the velocity profile and the surface temperature of a building with various fire intensities. This paper is an initial attempt to simulate a wildland-urban interface with a building structure, for various fire intensity values, using the FireFOAM solver. The impact of wildfire, with a wide range of fire intensity values, on building structures in terms of thermal load, both in terms of convection and radiation, have been examined and reported here.

\section{Geometrical Model and Boundary Conditions}

In the present investigation, the considered computational domain is a cubic structure with a size of $6 \times 6 \times 6 \mathrm{~m}$, which is the exact size of the Silsoe building in their experimental study [5]. It is worth noting that the Silsoe experiment was conducted in idealized conditions, namely a cubic building and flat terrain, and offers a collection of key scale data on the fundamental aerodynamic behaviour of low-rise structures under various wind loads.

As shown in Figure 1a, the building is located in the $50 \times 30 \times 25$ m computational domain. In the current study, according to the recommendations made by Richards and Norris [37], the boundaries of the considered domain are far enough from the building to avoid unfavourable boundary condition effects.

To analyse the impact of fire intensity [38] on the idealized building downstream from the fire, a $3 \mathrm{~m}$ width fire bed burning across the entire domain was positioned $20 \mathrm{~m}$ upstream from the building to simulate a line fire pattern. Methane with a heat of combustion equal to $45,435 \mathrm{~kJ} / \mathrm{kg}$ [39] was selected as a fuel to provide fire intensities of 10,14 , and $18 \mathrm{MW} / \mathrm{m}$, which are equivalent to a common wildfire with a spread rate of $0.75-0.8 \mathrm{~m} / \mathrm{s}$ and a fuel load of $0.4-0.6 \mathrm{~kg} / \mathrm{m}^{2}$ in a grassland. 
a)
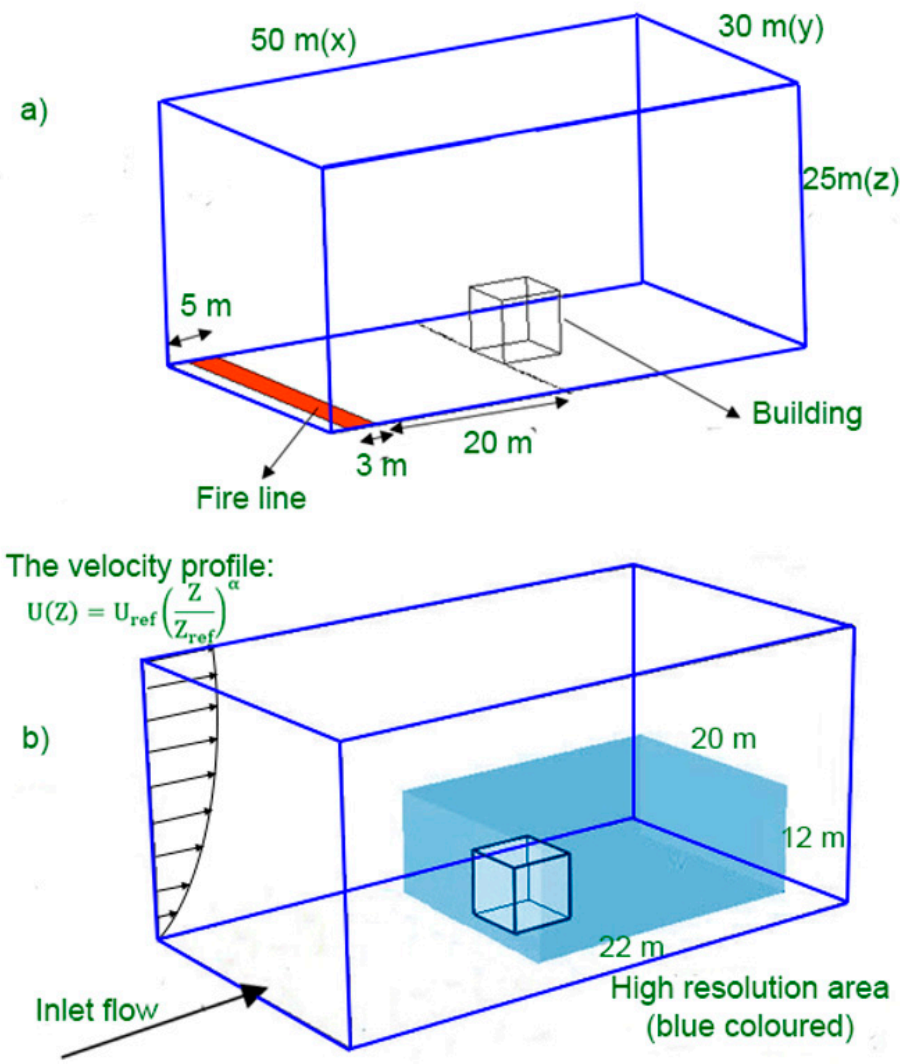

Figure 1. Schematic of the computational domain and the location of the building. (a) Total domain (b) Subdomain geometry.

The fire intensity value can be defined as follows [38]:

$$
\mathrm{I}=\mathrm{Rd}
$$

where, $\mathrm{d}$ is the burning strip of the fire line and $\mathrm{R}$ shows the combustion rate, which is heat of combustion multiplied by the burning fuel mass flow rate.

To obtain more accurate computational results near the cube and downstream from the fire, a near-wall region with a size of $22 \times 20 \times 12 \mathrm{~m}$ was considered as a high-resolution mesh subdomain (See Figure 1b) with a resolution five times higher than the other part of the domain. In order to reconstruct the turbulent flow fluctuations, a random noise with the mean flow velocity was applied at the domain inlet. Additionally, at the inlet domain, a power-law velocity profile was used as presented in Equation (2) and shown in Figure 1b.

To decrease the cost associated with simulating a transient process, the simulation of spatially evolving turbulent flows started with an inflow boundary that is transferred to a shorter distance upstream from the domain of interest [40]. In order to decrease the simulation cost and to obtain effective inflow data and turbulent inflow conditions, a simple and efficient method is to put random fluctuations on a desired mean velocity profile [41] The random fluctuation method is used in a number of numerical studies to simulate perturbations to the flow $[42,43]$.

The boundary layer at the atmosphere has been applied using a power-law velocity profile, as presented in Equation (2).

$$
\mathrm{U}(\mathrm{Z})=\mathrm{U}_{\mathrm{ref}}\left(\frac{\mathrm{Z}}{\mathrm{Z}_{\mathrm{ref}}}\right)^{\alpha}
$$

where, $Z_{\text {ref }}$ is the reference height equal to the building's height $(6 \mathrm{~m})$ [44], and $U_{\text {ref }}$ is the reference velocity which in this paper is considered $6 \mathrm{~m} / \mathrm{s} . \alpha$ is specified based on the 
terrain category of the experimental study [45] linked to the roughness of the terrain and considered as 0.16 . The initial temperature and velocity of the domain are considered to be $300 \mathrm{~K}$ and $0 \mathrm{~m} / \mathrm{s}$, respectively.

\section{Numerical Modelling}

In order to solve the equations governing the problem, the FireFOAM [46] solver of OpenFOAM, which is an open-source software, was used. FireFOAM is designed and developed for solving turbulent buoyant flows and diffusion flames and, more specifically, for simulating the dynamic of fire behavior. FireFOAM has also been shown to be an efficient tool in wildfire modelling [18].

To simulate turbulent flows, the Large Eddy Simulation (LES) method was applied. The Favre-filtered Navier-Stokes equations governed on the dynamic of the fire are written as a set of chemical species mass fraction, energy, momentum, and conservation equations of mass.

Continuity, momentum, energy, species and state equations [44] are presented in Equations (3) to (7).

$$
\begin{gathered}
\frac{\partial \bar{\rho}}{\partial t}+\frac{\partial\left(\bar{\rho} \tilde{u}_{i}\right)}{\partial x_{i}}=0 \\
\frac{\partial\left(\bar{\rho} \tilde{u}_{i}\right)}{\partial t}+\frac{\partial\left(\bar{\rho} \tilde{u}_{i} \tilde{u}_{j}\right)}{\partial x_{i}}=\frac{\partial}{\partial x_{j}}\left[\bar{\rho}\left(v+v_{t}\right)\left(\frac{\partial\left(\widetilde{u_{i}}\right)}{\partial x_{j}}+\frac{\partial\left(\tilde{u}_{j}\right)}{\partial x_{i}}-\frac{2}{3} \frac{\partial\left(\widetilde{u}_{k}\right)}{\partial x_{k}} \delta_{i j}\right)\right]-\frac{\partial(\bar{P})}{\partial x_{i}}+\bar{\rho} g_{i} \\
\frac{\partial(\bar{\rho})}{\partial t}+\frac{\partial\left(\bar{\rho} \widetilde{u}_{j} \widetilde{h}\right)}{\partial x_{j}}=\frac{D \bar{P}}{D t}+\frac{\partial}{\partial x_{j}}\left[\bar{\rho}\left(\alpha_{t}+\frac{v_{t}}{P r_{t}}\right)\left(\frac{\partial \widetilde{h}}{\partial x_{j}}\right)\right]+\dot{q}^{\prime \prime \prime}-\nabla \cdot \dot{q}_{r}^{\prime \prime} \\
\frac{\partial\left(\bar{\rho} \widetilde{Y_{m}}\right)}{\partial t}+\frac{\partial\left(\bar{\rho} \widetilde{u}_{j} \widetilde{Y_{m}}\right)}{\partial x_{j}}=\frac{\partial}{\partial x_{j}}\left[\bar{\rho}\left(D_{c}+\frac{v_{t}}{S c_{t}}\right) \frac{\partial\left(\widetilde{Y_{m}}\right)}{\partial x_{j}}\right]+\omega_{m} \\
\bar{P}=\bar{\rho} R \tilde{T}
\end{gathered}
$$

where, "-" and " $\sim$ " shows spatial and Favre filtering, respectively. P is the static pressure, $h$ represents the total enthalpy, $Y_{m}$ is the mass fraction of species $m, g$ represents the gravitational acceleration. $\mathrm{Pr}_{\mathrm{t}}, \mathrm{Sc}_{\mathrm{t}}, \mathrm{D}_{\mathrm{c}}, v, v_{\mathrm{t}}, \mathrm{P}, \mathrm{R}, \alpha_{\mathrm{t}}, \delta$ and $\omega_{\mathrm{m}}$ are the turbulent Prandtl number, turbulent Schmidt number, laminar diffusion coefficient, laminar viscosity, turbulent viscosity, density, gas constant, thermal diffusion coefficient, Kronecker delta and production/sink rate of species $m$ due to gas reactions, respectively. Coupled velocity and pressure is applied in the PIMPLE scheme which used by FireFOAM. In the current numerical model, the Large Eddy Simulation method (LES) was used. The differencing scheme of first order upwind was applied. Equation (4) can be written in the flow acceleration form as derived in Equation (8):

$$
\vec{a}=\frac{D \vec{u}}{D t}=\frac{-\nabla p}{\rho}+\vec{g}+\frac{\Phi}{\rho}
$$

where, "-" and " $\sim$ " shows spatial and Favre filtering, respectively. P is the static pressure, $h$ represents the total enthalpy, $Y_{m}$ is the mass fraction of species $m$, $g$ represents the gravitational acceleration. $\mathrm{Pr}_{\mathrm{t}}, \mathrm{Sc}_{\mathrm{t}}, \mathrm{D}_{\mathrm{c}}, v, v_{\mathrm{t}}, \mathrm{P}, \mathrm{R}, \alpha_{\mathrm{t}}, \delta$ and $\omega_{\mathrm{m}}$ are the turbulent Prandtl number, turbulent Schmidt number, laminar diffusion coefficient, laminar viscosity, turbulent viscosity, density, gas constant, thermal diffusion coefficient, Kronecker delta and production/sink rate of species $m$ due to gas reactions, respectively. Coupled velocity and pressure is applied in the PIMPLE scheme which used by FireFOAM. In the current numerical model, the Large Eddy Simulation method (LES) was used. The differencing scheme of 
first order upwind was applied. Equation (4) can be written in the flow acceleration form as derived in Equation (8):

$$
\vec{a}=\frac{D \vec{u}}{D t}=\frac{-\nabla p}{\rho}+\vec{g}+\frac{\Phi}{\rho}
$$

where, $\vec{a}$ represents acceleration of the flow, $u$ represents the flow velocity, $\nabla p$ is pressure gradient, and $\Phi$ is viscous shear stress.

\section{Verification}

To verify the numerical model, a detailed comparison between pressure coefficients in the present study and two sets of experimental measurements of Castro and Robins [47] and Richards and Hoxey [5] was made. The numerical results of this study were also verified with the numerical findings of $\mathrm{He}$ et al. [11] and are shown in Figure 2. As mentioned, two sets of experimental investigations on pressure along the vertical and horizontal centrelines of the Silsoe cube of Richards and Hoxey [5] and Castro and Robins [47] were used to examine the irrotational and sheared turbulent flows around a cube representing an idealized building. In addition to these two experimental studies which were conducted in the absence of fire, the results of the current study were validated against the numerical study of He et al. [11], who modelled the interactions between bushfires, wind, and building structures with the Fire Dynamic Simulation (FDS) software package.

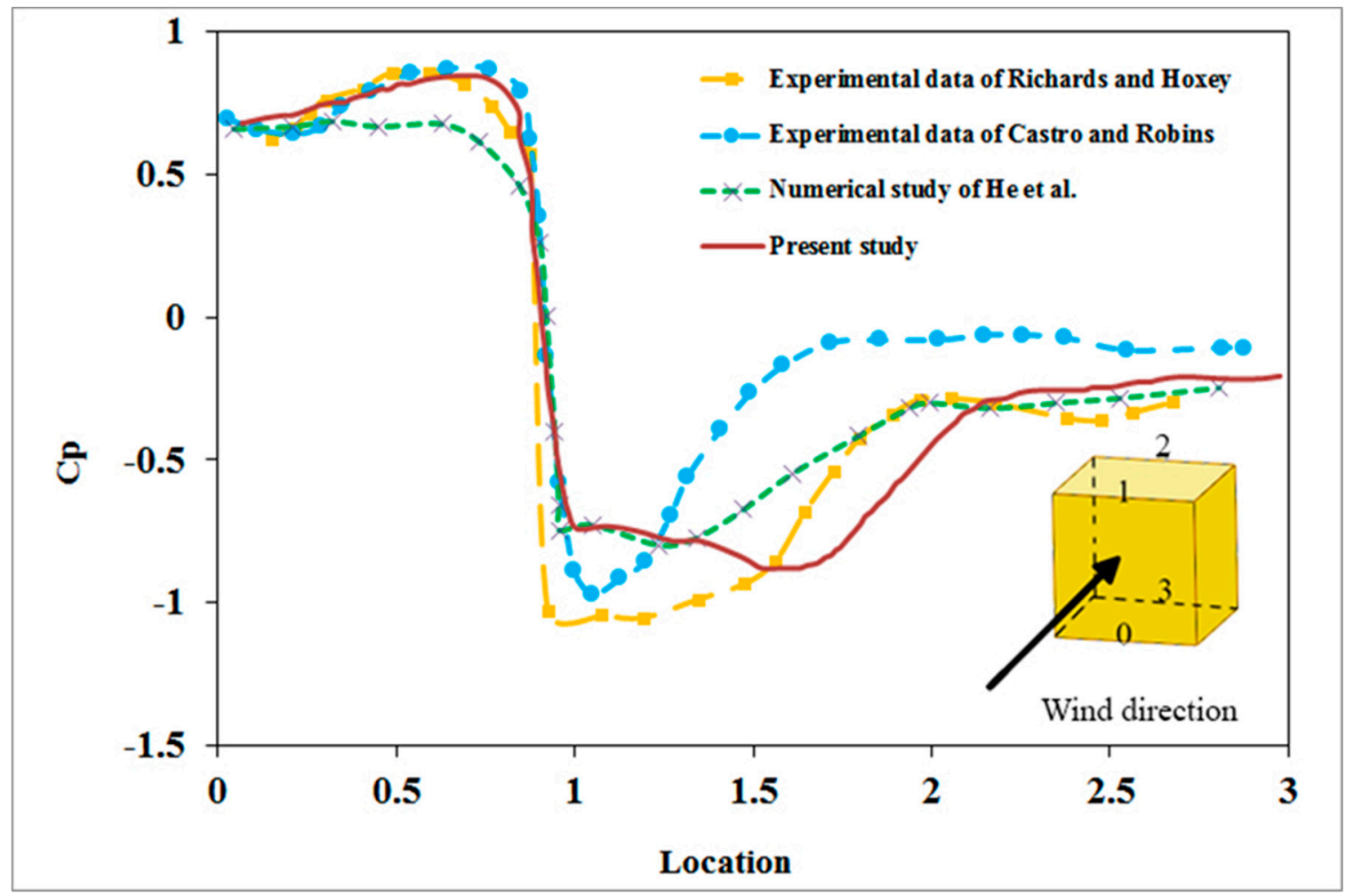

Figure 2. Comparison of the mean pressure coefficient for the experimental studies of [5,47], the numerical simulation of [11].

He et al. [11], calculated the pressure coefficient distribution around a building with the reference velocity of the wind equal to $9.52 \mathrm{~m} / \mathrm{s}$, under no-fire conditions and validated their outcomes with the other experimental studies.

It is worth mentioning that the validation of the current numerical model was also carried out in the absence of fire effect by comparing the results of full-scale Silsoe cubic building of Richards and Hoxey [48]. Since the Eddy Dissipation Concept (EDC) is mainly 
regulated by turbulent mixing, the characteristics of the fire dynamic are tightly linked to the building's aerodynamics. Therefore, the pressure distribution along the building in a no-fire scenario is an applicable gauge, indicating the accuracy and validity of the numerical findings.

The numerical calculations of the pressure coefficient alongside the centrelines over the rear, top, and front surfaces of the building (demonstrated by the $0-1-2-3$ solid lines) are plotted in Figure 3. The results of previous numerical studies are also plotted in Figure 3 with those computed from the various grids considered in the current study. Even though there is a good agreement between the simulated data and experimental investigation on building faces, perceptible inconsistencies still exist across the roof face of the cube (1-2 line). These inconsistencies were also observed in the other studies incorporated in Figure 2 and can be linked to the high scatter of wind velocity in the experimental measurements and direction data. This substantially impacts the separation regions in the corners and the pressure distribution over the roof of the idealized building (the cube). In addition, as the oscillations of wind pressure on the cube are mostly due to large-scale shifts [49], the size of the computational domain can restrict the size of the largest eddy and undesirably influence the results. The maximum error occurs at the location 1.25 and is about $18 \%$.

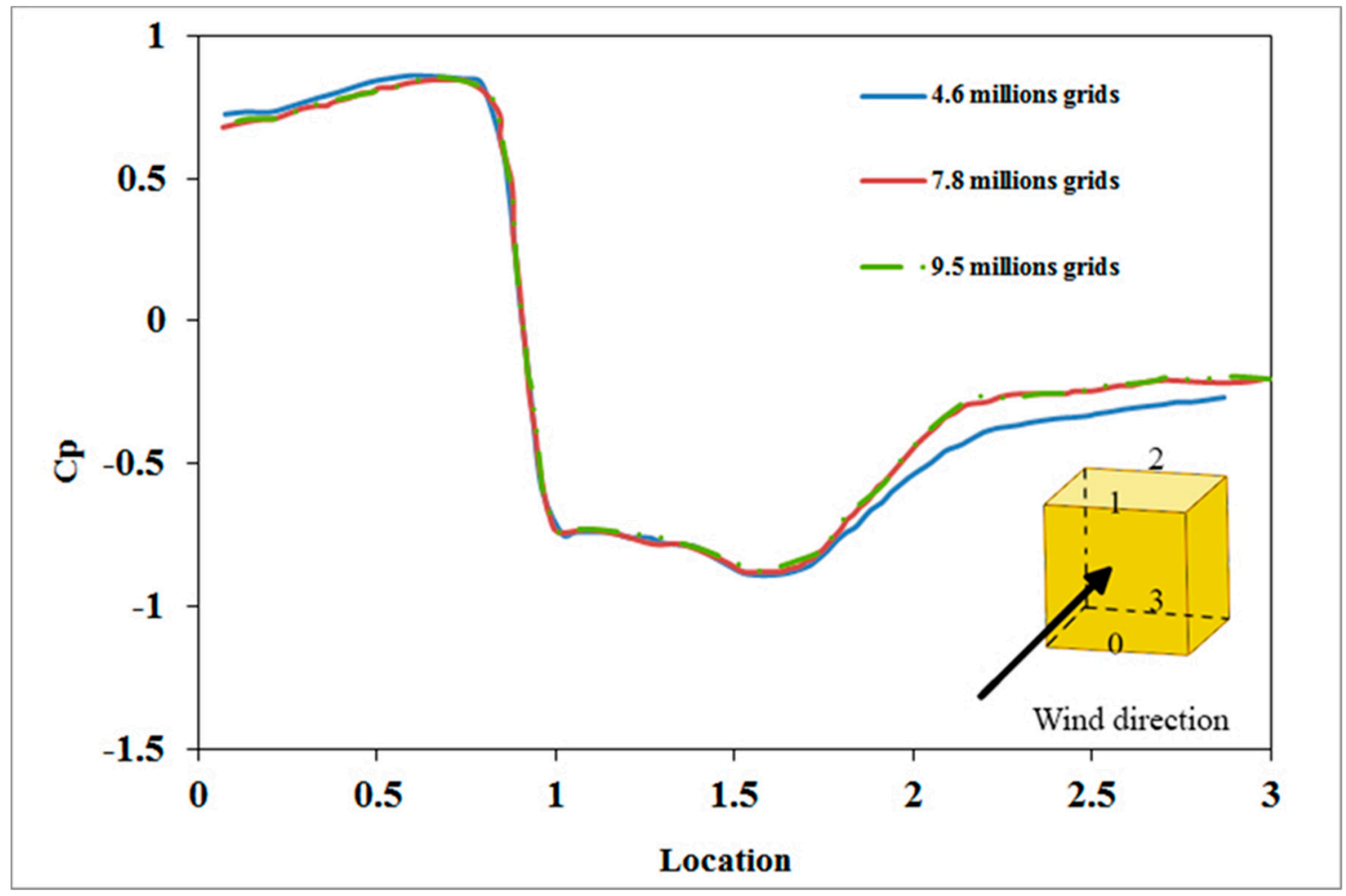

Figure 3. Comparison of the mean pressure coefficient for the three different grids number for the presented study.

In order to achieve validation in the case with fire, a comparison between the data reported in the work of Morvan [17] and the present investigation is also made and reported in Table 1. The flame height for various wind velocities of $4.5,6$, and $7.5 \mathrm{~m} / \mathrm{s}$ is reported for the fire intensity of $10 \mathrm{MW} / \mathrm{m}$ [50]. As can be seen, the results of the current study are significantly close to the published study [17] with a maximum error of $8 \%$.

To reduce numerical uncertainties, a mesh sensitivity analysis was performed with three sets of structured mesh size into the domain: 4,600,000,7,800,000, and 9,500,000. The meshes are uniform in all directions. As mentioned previously, the subdomain mesh reso- 
lution is five time higher that the main domain which in three grid sets of $(176 \times 160 \times 96$, $210 \times 191 \times 114$, and $224 \times 204 \times 122$ ) were tested.

Table 1. Comparison of the flame height, as functions of the wind velocity, between published data [17] and the present study, for the fire intensity of $10 \mathrm{MW} / \mathrm{m}$.

\begin{tabular}{ccc}
\hline & Published Data [17] & Present Study \\
\hline Flame height (wind velocity $4.5 \mathrm{~m} / \mathrm{s}$ ), m & 1.4 & 1.5 \\
Flame height (wind velocity $6 \mathrm{~m} / \mathrm{s}$ ), m & 1.25 & 1.15 \\
Flame height (wind velocity $7.5 \mathrm{~m} / \mathrm{s}$ ), m & 0.85 & 0.8 \\
\hline
\end{tabular}

The results of the grid independency study indicate that increasing the number of grid cells initially leads to an increase in the mean pressure coefficient, while a further increase in the number of cells marginally affects the pressure coefficient profile.

\section{Result and Discussion}

The focus of this work is to develop a validated, CFD-based, numerical model for simulating the effect of wind driven wildfire intensity fire intensity at the WUI. From a modelling point of view a distinguishing feature of wildfires, when it comes to their effect on structures at the WUI, is fire intensity. The work reported here focused on the fire characteristics and the downstream aerodynamic behaviour in the presence of a building structure for various fire intensity values to shed light on the impact of the intensity of the fire line on the near built structure and the generated hazard.

Figure 4 shows the effects of various fire intensities on the temperature distribution caused by the fire line in a domain with a constant cross wind velocity of $U_{\text {ref }}=6 \mathrm{~m} / \mathrm{s}$. As can be seen in this Figure, by increasing the fire intensity, the downstream temperature increases near the building. Looking at the results presented in Figure 4 in more detail, the higher fire intensities affect the downstream temperature significantly so that at the back of the building, there is a substantially high temperature area of more than $1000 \mathrm{~K}$. Comparing Figures 4 and 5 at the case with the fire intensity of $18 \mathrm{MW} / \mathrm{m}$, it can be is seen that a wake is created at the back of the building which results in a low pressure area at this region. Given the mentioned point, the turbulent high temperature flow is observed at the back of the building with the lack of oxygen which is consumed at the upstream.

Figure 5 shows the contours of vertical transects of instantaneous streamwise velocity component ( $\mathrm{Ux}$ = velocity component in the $\mathrm{X}$ direction) and corresponding velocity vectors in the flat terrain for various fire intensities of 10,14 , and $18 \mathrm{MW} / \mathrm{m}$, in a constant cross wind reference velocity of $6 \mathrm{~m} / \mathrm{s}$. As shown in this figure, by increasing the intensity of the fire, the velocity of the hot gas plume increases. The main reason behind the observed trend is the low-pressure area behind the fire line as a result of high temperature air, which causes low-density air and makes an extra stream behind of the fire plume. This accelerates the air velocity downstream from the fire source.

Downstream from the fire, at the back of the building, a recirculation region as a result of reverse flow could be seen. This is mainly occurred due to a pressure drop and wake as well as buoyant instability [51], which leads to the generation of a hot air region behind the building. The above phenomenon increases with an increase in fire intensities due to the increase in wind velocity, as a result of the change in the buoyancy force direction. 


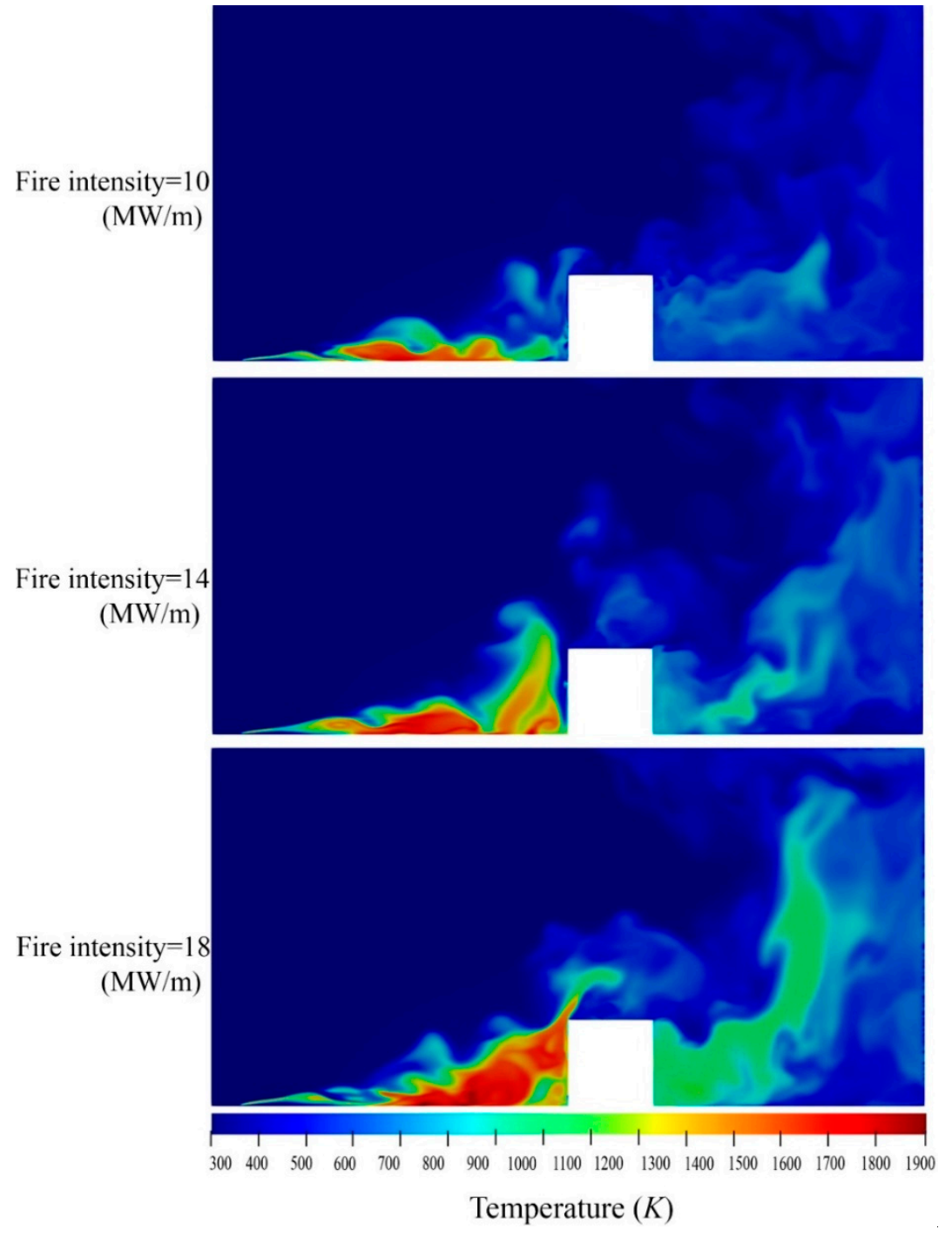

Figure 4. Temperature distribution for the reference velocity $U_{\text {ref }}=6 \mathrm{~m} / \mathrm{s}$ for various fire intensities.

To obtain the ratio of the inertial force and thermal buoyancy in fire, the dimensionless Froude number [52] can be used which is defined as follows [53]:

$$
\mathrm{Fr}=\frac{\mathrm{Ux}}{\sqrt{\mathrm{gL}_{\mathrm{w}}}}
$$

where, $U$ represents the velocity, $g$ is the acceleration of gravity, and $L_{w}$ is equal to the width of the fire line perpendicular to the wind. The fire intensity effects on the Froude number distribution can be seen in changing in the air flow velocities corresponded to the fire plume, which depend on the air temperature.

The Froude number distribution in the domain for the different fire intensities of 10, 14 , and $18 \mathrm{MW} / \mathrm{m}$ and a constant reference velocity $U_{\text {ref }}=6 \mathrm{~m} / \mathrm{s}$ are shown in Figure 6 . The dimensionless Froude number specifies the ratio of the inertial force and the thermal buoyancy in fire. As can be seen, increasing the intensity of the fire leads to an increase in Froude number. This is associated with the increase in air velocity, which is caused by hot temperature streams as a result of buoyancy force. The hot temperature stream has a lower density which can boost the buoyancy force, resulting in a more turbulent area and increases the flow velocity, and finally affects the ratio of the inertial force and the thermal buoyancy. 
Fire intensity $=10$

$(\mathrm{MW} / \mathrm{m})$

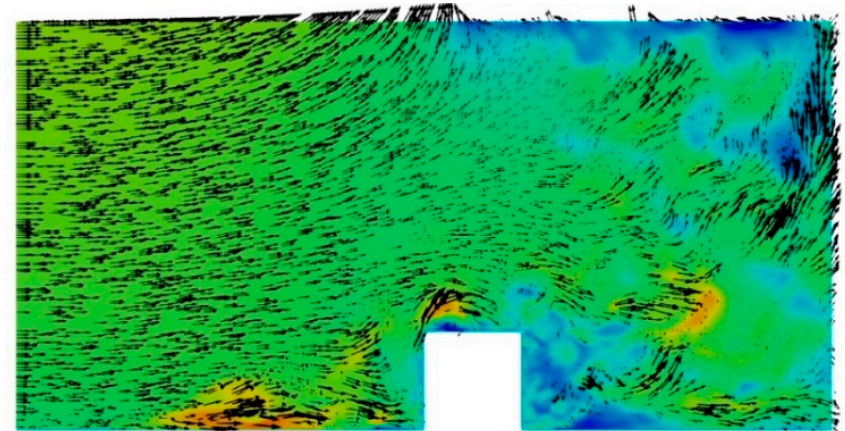

Fire intensity $=14$

$(\mathrm{MW} / \mathrm{m})$

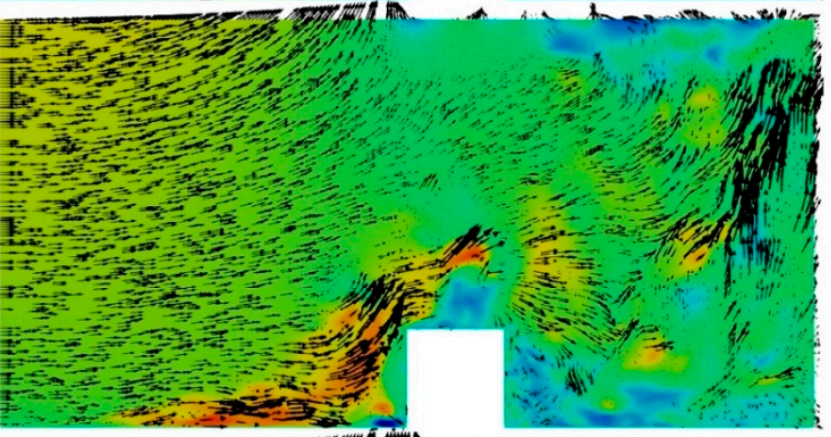

Fire intensity $=18$

$(\mathrm{MW} / \mathrm{m})$

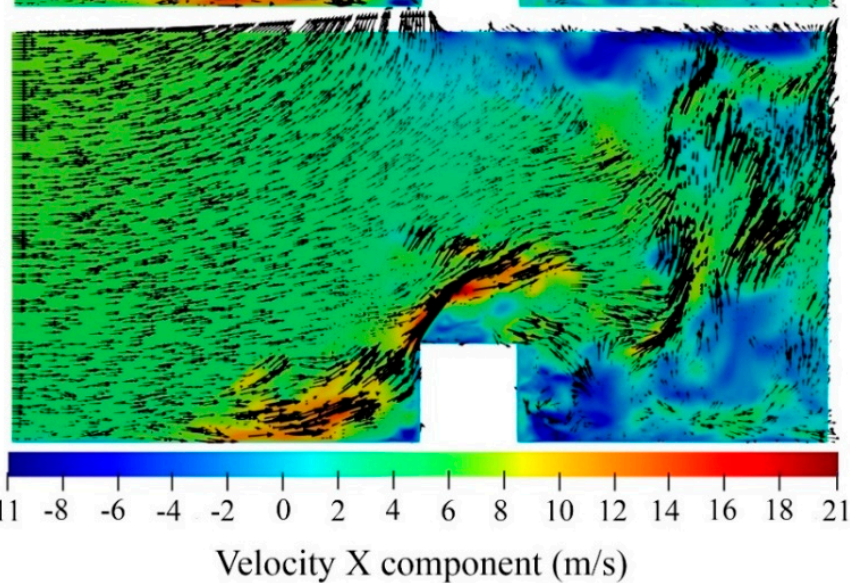

Figure 5. Vertical transects of instantaneous streamwise velocity component (Ux) for the reference velocity $U_{\text {ref }}=6 \mathrm{~m} / \mathrm{s}$ for various fire intensities.

Figure 7 shows the contours of temperature distribution on the ground, in the vicinity of the building and downstream from the fire. As can be seen, increasing the fire intensity results in an increase in the area with higher temperature near the building. This is linked to the combination of two main factors: first, obviously, a higher fire intensity physically means prolonged flames and as a result, an increase in heat transfer to the ground.

The second factor is that by raising the fire intensity, the wind velocity downstream from the fire line increases, which leads to an increase in the Coanda effect [54]. In other words, in addition to the wind force, the buoyancy force intensifies the wind velocity, and contributes to the Coanda effect, which increases the attachment of the flame to the ground.

The integrated temperature is defined as the mean temperature of the whole surface. Due to the fact that each point of the surface has a different temperature, the integrated temperature is calculated in these simulations. 
Fire intensity $=10$

$(\mathrm{MW} / \mathrm{m})$
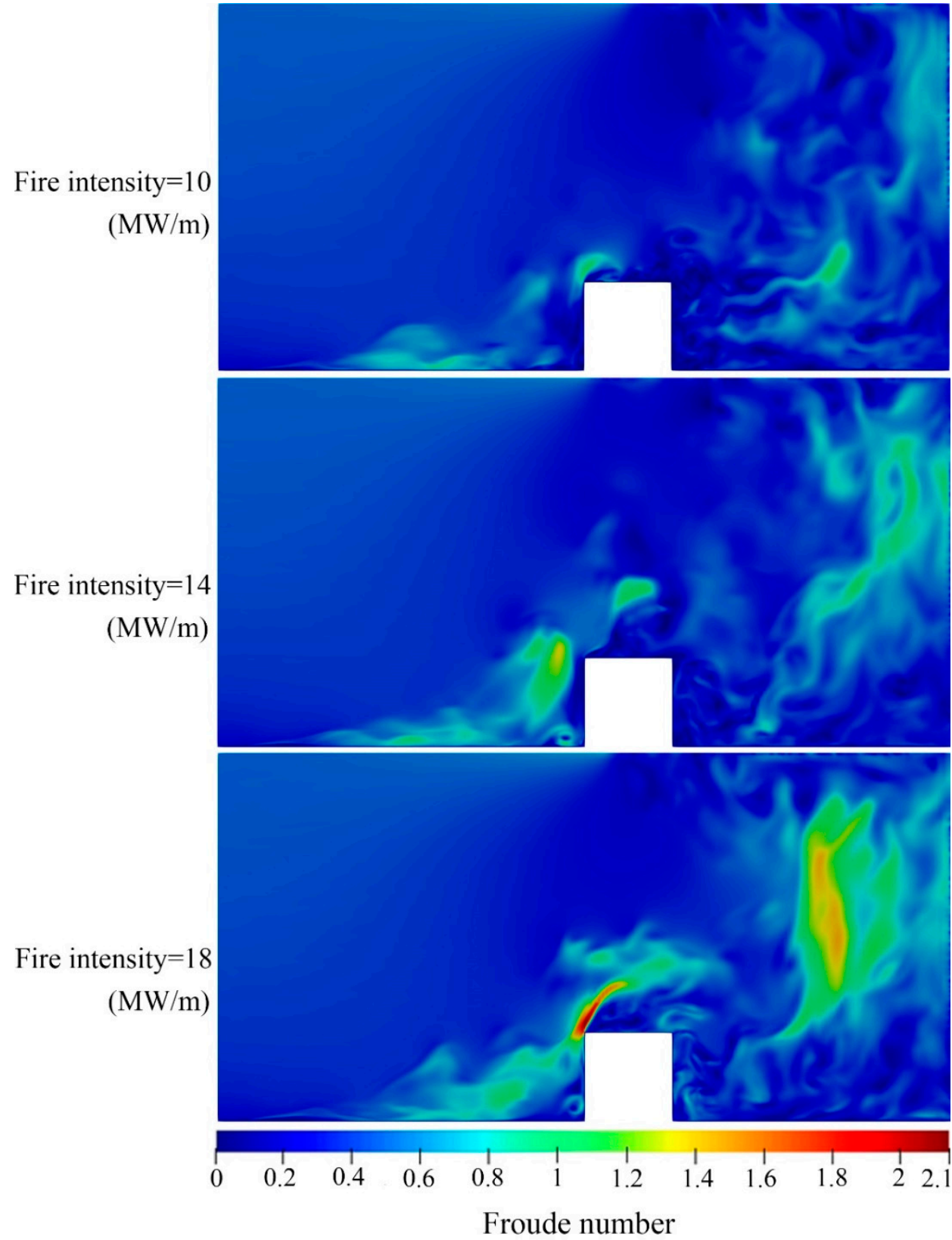

Figure 6. Contours of Froude number distribution for fire intensities of 10, 14, and $18 \mathrm{MW} / \mathrm{m}$.

Figure 8 indicates the integrated temperature on the ground at the domain and the building surface for three different fire intensities. As seen, the overall trend observed in the cases shown in Figure 8 aligns well with the description of Figure 7, so that by increasing the fire intensity, the mean temperature of the ground and the surface temperature of the building increase. Increasing fire intensity from 10 to $18 \mathrm{MW} / \mathrm{m}$, raises the integrated temperature on the ground and the surface of the building by $26 \%$, and $69 \%$, respectively. Looking at Figure 8 in more detail, there is a sharp increase in the integrated temperature of the building surface for the higher fire intensity values. This is due to the increase in fire plume length enhanced by the wind velocity, which is carried toward the building area that is perpendicular to the ground. Generally speaking, fire intensity values and integrated temperature of the ground and the building surface are directly related. 

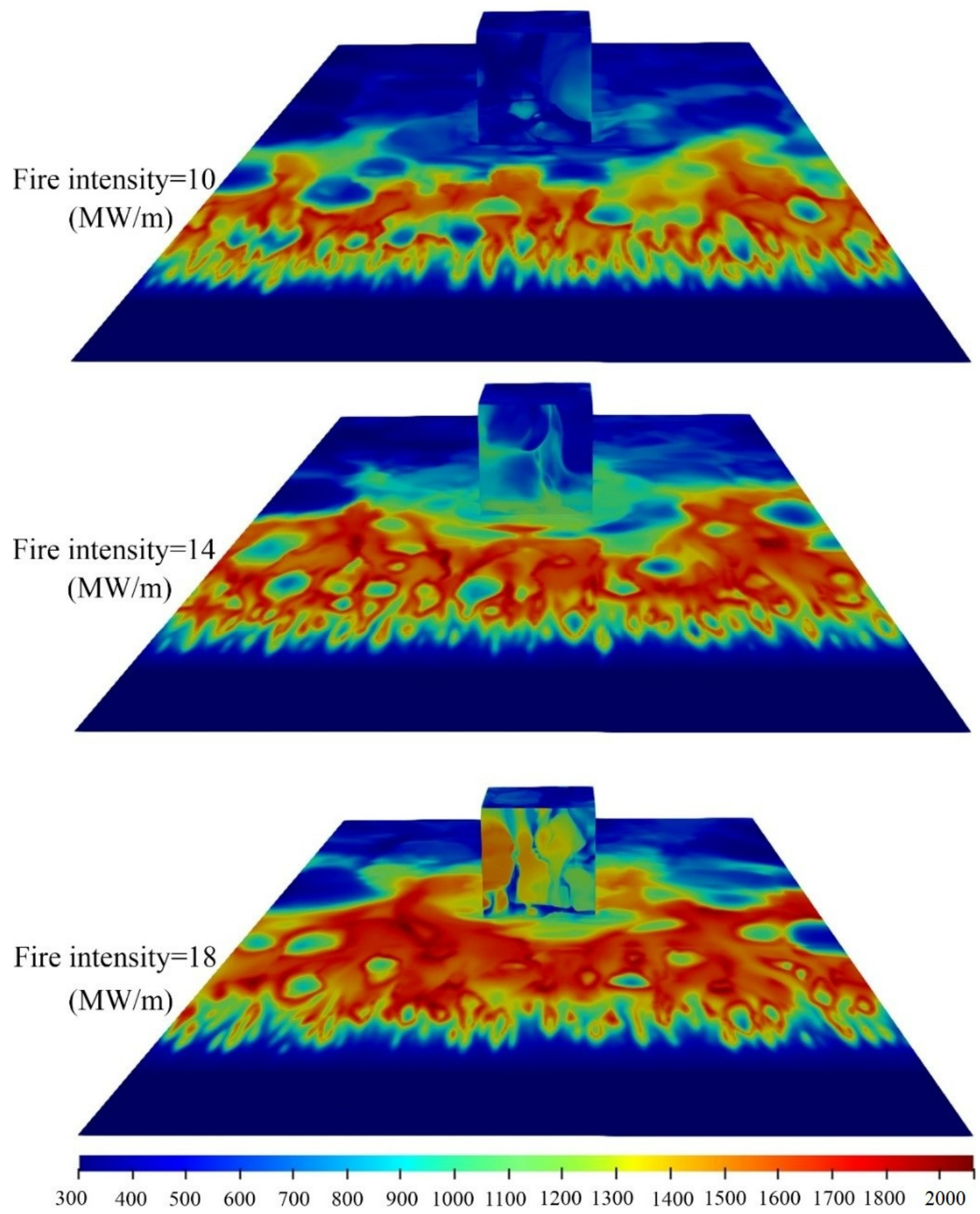

Temperature $(K)$

Figure 7. Temperature distribution on the ground in a constant $U_{\text {ref }}=6 \mathrm{~m} / \mathrm{s}$ and three different fire intensities. 


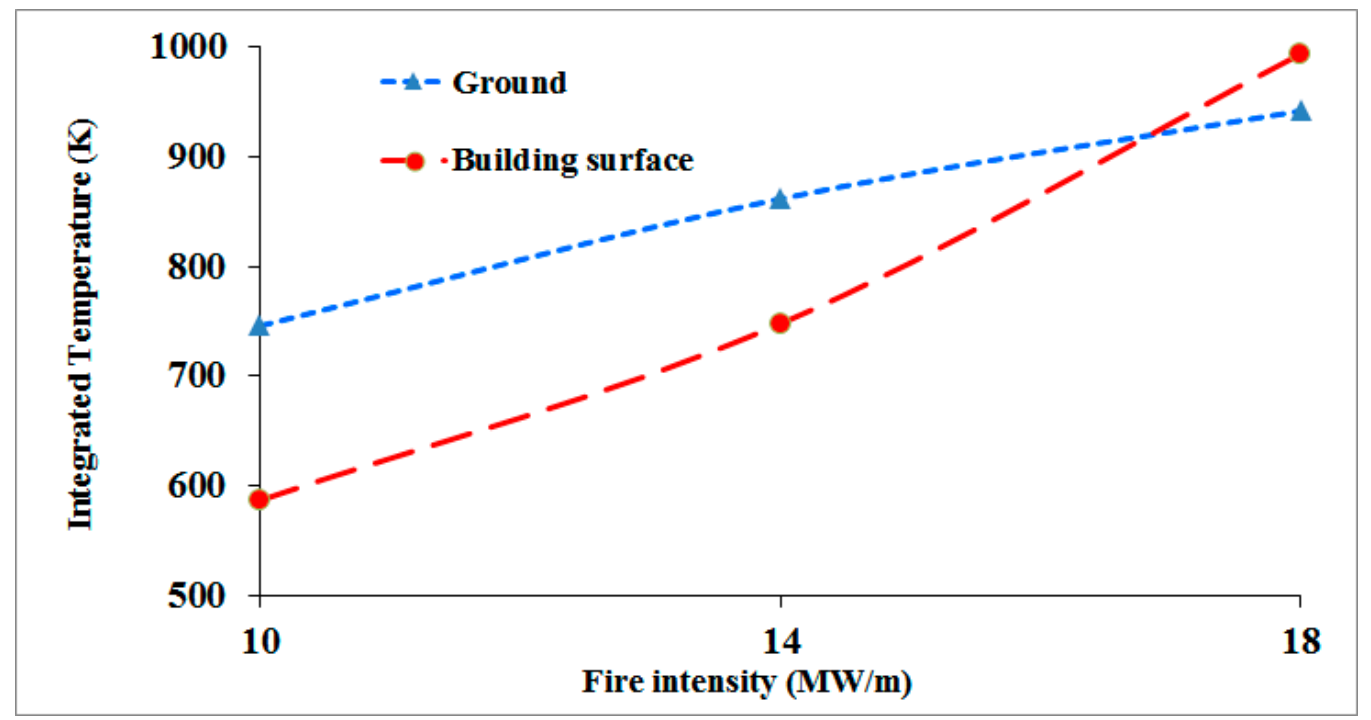

Figure 8. Integrated temperature on the ground at the considered domain and surface building for a constant $\mathrm{U}_{\text {ref }}=6 \mathrm{~m} / \mathrm{s}$ and fire intensities 10,14 and $18 \mathrm{MW} / \mathrm{m}$.

Figure 9 shows the temperature distribution at the surface of the building for different fire intensities. Quite obviously, the front surface of the building has the highest temperature; this is due to having the highest view factor for the radiation heat transfer from the fire source. By increasing the fire intensity, the maximum temperature on the building surface increases. The random appearance of the provided contours is caused by instabilities between the buoyancy force and inertial wind flow, which create turbulent flames.

Basically, wildfire risk at the WUI (Wildland-Urban Interface) can be described as a combined function of fire probability, fire intensity, and fire effects [49]. That is, a wildfire risk evaluation at the WUI evaluates both the likelihood and extent of wildfire-related impacts. This work is an initial attempt at understanding the impact of fire intensity of a wind driven wildfire at the WUI. The results outlined in this study bring up some inquiries on the rationality of risk management measures, such as the one in Australian Standard AS 3959, Construction of Buildings in bushfire-prone areas [55].

In AS3959, the flames are basically represented as a hot surface inclined at a fixed angle that is obtained by the balance between wind velocity and fire intensity. In contrast, the numerical results described in this research emphasize the transient nature of wildfire spread and suggest that a wildfire can instantly generate flames that vary between being attached to the ground and more vertically positioned upwind from a structure.

Flames that are attached to the ground have a higher likelihood to suffuse a structure with convective heat transfer. A higher pulse frequency exists between attached and separated flame regimes and happens upwind from a structure, proposing that convective heating can have a substantial impact on the heat contact of building façades right in the trail of an approaching fire front. The present study proposes a practical framework for assessing the wildfire intensity effects on WUI areas.

The mean pressure coefficient on the building for various fire intensity values are presented in Figure 10. By increasing the fire intensity, the pressure coefficient is increased. This is mainly due to decrease in the air pressure around the building at the downstream from the fire. The maximum value of the mean pressure coefficient occurs in front of the building. This is due to the higher value of the local pressure. 
Fire intensity $=10$ $(\mathrm{MW} / \mathrm{m})$

Fire intensity $=14$

$(\mathrm{MW} / \mathrm{m})$

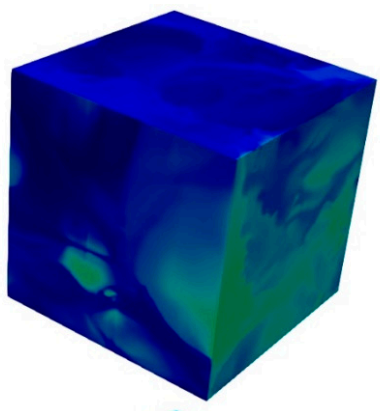

Fire intensity $=18$

$(\mathrm{MW} / \mathrm{m})$
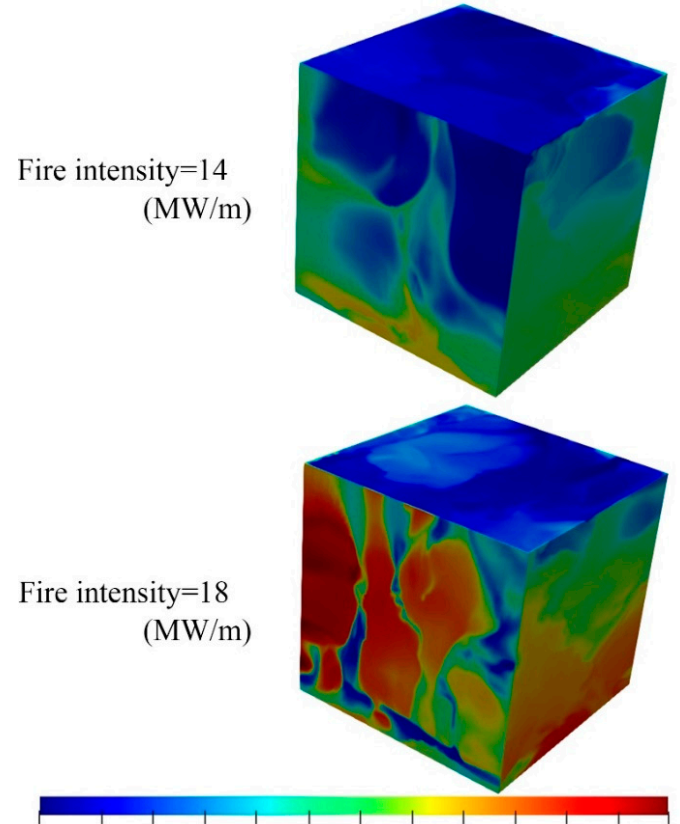

$\begin{array}{llllllll}380 & 500 & 600 & 700 & 800 & 9001000110012001300140015001600\end{array}$

Temperature $(K)$

Figure 9. Temperature distribution on the building for three different fire intensity values.

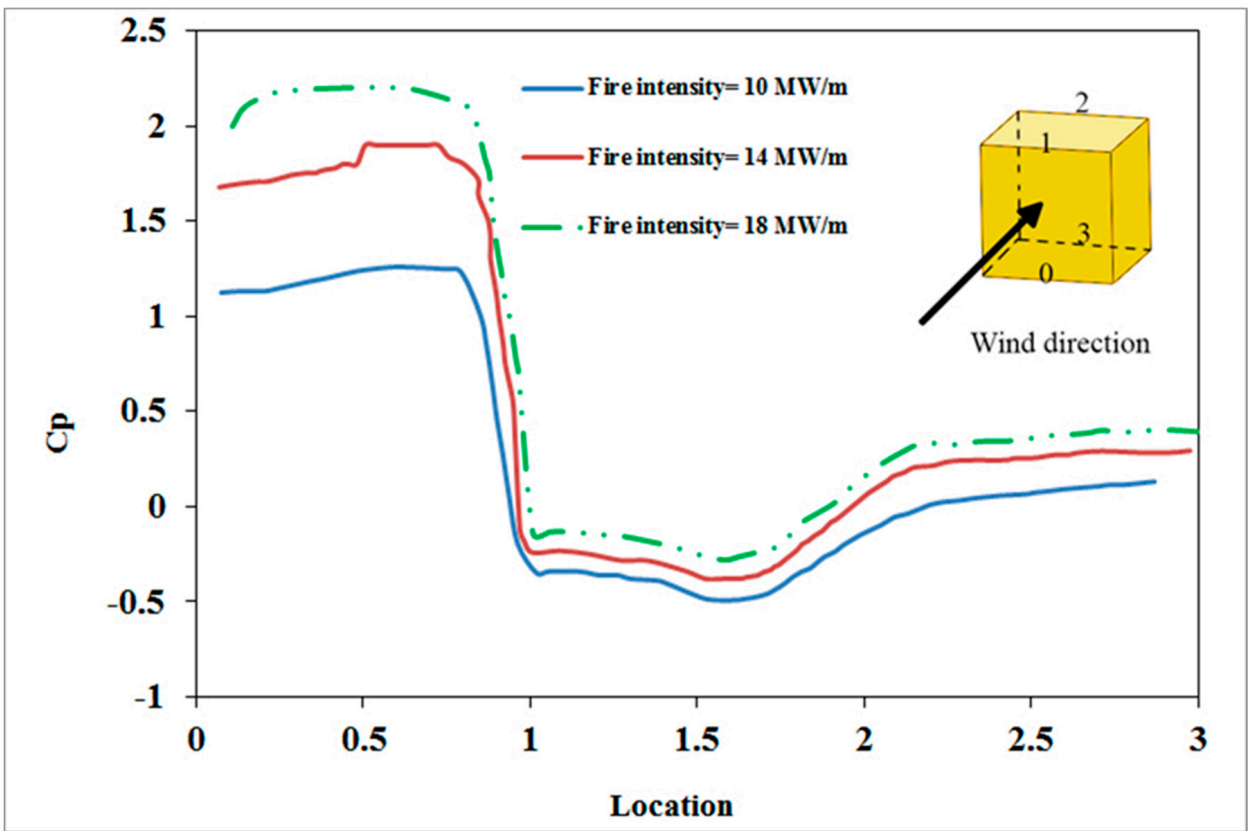

Figure 10. Mean pressure coefficient for fire intensities 10, 14 and $18 \mathrm{MW} / \mathrm{m}$. 


\section{Conclusions}

In the present study, the effect of fire the intensity of a wind driven surface fire and its interaction with an idealized structure and the downstream temperature distribution and velocities at the wildland-urban interface was numerically investigated.

The fire intensities of 10,14 , and $18 \mathrm{MW} / \mathrm{m}$ for a constant wind-field with a reference velocity of $6 \mathrm{~m} / \mathrm{s}$ was simulated using the FireFOAM CFD solver, which is a solver of OpenFOAM platform, that is designed for simulating fire. All the cases were simulated to predict the impact of the changing intensity of the fire front and its impact on a cubic idealized structure downstream from the fire source.

The main outcomes of this study can be summarized as follows:

- The simulated data have an acceptable agreement with the experimental measurements for cold flows. The maximum error between the numerical data and experimental results is $18 \%$.

- The higher fire intensities affect the downstream temperature significantly in a way that even at the back of the building, a region of extremely high temperatures can be observed.

- By increasing the fire intensity, the velocity of the air stream increases, which is linked to a low-pressure area behind the fire front as a result of hot air. This hot air region causes low-density air and makes an extra stream behind the fire plume.

- Increasing fire intensity results in an increase in Froude number. This is due to the increase in vertical air velocity, which is caused by hot temperature stream as a result of buoyancy force.

- Increasing fire intensity from $10 \mathrm{MW} / \mathrm{m}$ to $18 \mathrm{MW} / \mathrm{m}$ raises the integrated temperature on the ground and on the surface of the building by $26 \%$, and $69 \%$, respectively.

Author Contributions: Methodology, M.G. and A.S.; formal analysis, A.E.-n. and M.G.; writingoriginal draft preparation, A.E.-n. and M.G.; writing-review and editing, M.G., A.S., S.A.F.; visualization, A.S., M.G.; supervision, M.G., A.S. and S.A.F. All authors have read and agreed to the published version of the manuscript.

Funding: This research received no external funding.

Institutional Review Board Statement: Not applicable.

Informed Consent Statement: Not applicable.

Data Availability Statement: The data presented in this study are available on request from the corresponding author.

Acknowledgments: The current work is supported by computational resources provided by the Australian Government in the University of New South Wales under the National Computational Merit Allocation Scheme.

Conflicts of Interest: The authors declare no conflict of interest.

\section{References}

1. Caton, S.E.; Hakes, R.S.P.; Gorham, D.J.; Zhou, A.; Gollner, M.J. Review of Pathways for Building Fire Spread in the Wildland Urban Interface Part I: Exposure Conditions. Fire Technol. 2016, 53, 429-473. [CrossRef]

2. Dennison, P.E.; Brewer, S.C.; Arnold, J.D.; Moritz, M.A. Large wildfire trends in the western United States, 1984-2011. Geophys. Res. Lett. 2014, 41, 2928-2933. [CrossRef]

3. Westerling, A.L. Increasing western US forest wildfire activity: Sensitivity to changes in the timing of spring. Philos. Trans. R. Soc. B Biol. Sci. 2016, 371, 20150178. [CrossRef]

4. Hakes, R.S.P.; Caton, S.E.; Gorham, D.J.; Gollner, M.J. A Review of Pathways for Building Fire Spread in the Wildland Urban Interface Part II: Response of Components and Systems and Mitigation Strategies in the United States. Fire Technol. 2016, 53, 475-515. [CrossRef]

5. Richards, P.; Hoxey, R. Pressures on a cubic building-Part 1: Full-scale results. J. Wind. Eng. Ind. Aerodyn. 2011, 102, 72-86. [CrossRef]

6. Hostikka, S.; Mangs, J.; Mikkola, E. Comparison of Two and Three Dimensional Simulations of Fires at Wildland Urban Interface. Fire Saf. Sci. 2008, 9, 1353-1364. [CrossRef] 
7. Fryanova, K.; Perminov, V. Impact of forest fires on buildings and structures. Mag. Civ. Eng. 2017, 75, 15-22.

8. Ghodrat, M.; Shakeriaski, F.; Nelson, D.; Simeoni, A. Existing Improvements in Simulation of Fire-Wind Interaction and Its Effects on Structures. Fire 2021, 4, 27. [CrossRef]

9. Frangieh, N.; Accary, G.; Morvan, D.; Méradji, S.; Bessonov, O. Wildfires front dynamics: 3D structures and intensity at small and large scales. Combust. Flame 2019, 211, 54-67. [CrossRef]

10. Mell, W.E.; Manzello, S.L.; Maranghides, A.; Butry, D.; Rehm, R.G. The wildland-Urban interface fire problem-Current approaches and research needs. Int. J. Wildland Fire 2010, 19, 238-251. [CrossRef]

11. He, Y.; Kwok, K.C.S.; Douglas, G.; Razali, I.M. Numerical investigation of bushfire-wind interaction and its impact on building structure. Fire Saf. Sci. 2011, 10, 1449-1462. [CrossRef]

12. Clark, K.L.; Heilman, W.E.; Skowronski, N.S.; Gallagher, M.R.; Mueller, E.; Hadden, R.M.; Simeoni, A. Fire Behavior, Fuel Consumption, and Turbulence and Energy Exchange during Prescribed Fires in Pitch Pine Forests. Atmosphere 2020, 11, 242. [CrossRef]

13. Edalati-nejad, A.; Ghodrat, M.; Simeoni, A. Numerical Investigation of the Effect of Sloped Terrain on Wind-Driven Surface Fire and Its Impact on Idealized Structures. Fire 2021, 4, 94. [CrossRef]

14. Ghodrat, M.; Shakeriaski, F.; Nelson, D.; Simeoni, A. Experimental and Numerical Analysis of Formation and Flame Precession of Fire Whirls: A Review. Fire 2021, 4, 43. [CrossRef]

15. Abouali, A.; Viegas, D.X.; Raposo, J.R. Analysis of the wind flow and fire spread dynamics over a sloped-ridgeline hill. Combust. Flame 2021, 234, 111724. [CrossRef]

16. Cheney, N.; Gould, J.; Catchpole, W. The Influence of Fuel, Weather and Fire Shape Variables on Fire-Spread in Grasslands. Int. J. Wildland Fire 1993, 3, 31-44. [CrossRef]

17. Morvan, D. A numerical study of flame geometry and potential for crown fire initiation for a wildfire propagating through shrub fuel. Int. J. Wildland Fire 2007, 16, 511-518. [CrossRef]

18. El Houssami, M.; Lamorlette, A.; Morvan, D.; Hadden, R.M.; Simeoni, A. Framework for submodel improvement in wildfire modeling. Combust. Flame 2018, 190, 12-24. [CrossRef]

19. Zazali, H.H.; Towers, I.N.; Sharples, J.J. A critical review of fuel accumulation models used in Australian fire management. Int. J. Wildland Fire 2021, 30, 42. [CrossRef]

20. Gong, J.; Cao, J.; Zhai, C.; Wang, Z. Effect of moisture content on thermal decomposition and autoignition of wood under power-law thermal radiation. Appl. Therm. Eng. 2020, 179, 115651. [CrossRef]

21. Van Wagner, C.E. Prediction of crown fire behavior in conifer stands. In Proceedings of the 10th Conference on Fire and Forest Whitewood = Compte Rendu du 10ieme Congress sur les Incendies et la Meterologie Forestiere/Editeurs, Ottawa, ON, Canada, 17-21 April 1989.

22. Cruz, M.G.; Alexander, M.E.; Wakimoto, R.H. Assessing canopy fuel stratum characteristics in crown fire prone fuel types of western North America. Int. J. Wildland Fire 2003, 12, 39-50. [CrossRef]

23. Morvan, D. Numerical study of the effect of fuel moisture content (FMC) upon the propagation of a surface fire on a flat terrain. Fire Saf. J. 2013, 58, 121-131. [CrossRef]

24. Goldammer, J.G.; De Ronde, C. Wildland Fire Management Handbook for Sub-Sahara Africa; African Minds: Cape Town, South Africa, 2004; Available online: https:/ /gfmc.online/latestnews/GFMC-Wildland-Fire-Management-Handbook-Sub-Sahara-Africa-20 04.pdf (accessed on 10 January 2022).

25. Trollope, W.S.W.; Tainton, N.M. Effect of fire intensity on the grass and bush components of the Eastern Cape thornveld. J. Grassl. Soc. S. Afr. 1986, 3, 37-42. [CrossRef]

26. Overholt, K.J.; Cabrera, J.; Kurzawski, A.; Koopersmith, M.; Ezekoye, O.A. Characterization of Fuel Properties and Fire Spread Rates for Little Bluestem Grass. Fire Technol. 2012, 50, 9-38. [CrossRef]

27. Marino, E.; Dupuy, J.-L.; Pimont, F.; Guijarro, M.; Hernando, C.; Linn, R. Fuel bulk density and fuel moisture content effects on fire rate of spread: A comparison between FIRETEC model predictions and experimental results in shrub fuels. J. Fire Sci. 2012, 30, 277-299. [CrossRef]

28. Weise, D.R.; Koo, E.; Zhou, X.; Mahalingam, S.; Morandini, F.; Balbi, J.-H. Fire spread in chaparral—A comparison of laboratory data and model predictions in burning live fuels. Int. J. Wildland Fire 2016, 25, 980-994. [CrossRef]

29. Banerjee, T.; Heilman, W.; Goodrick, S.; Hiers, J.K.; Linn, R. Effects of canopy midstory management and fuel moisture on wildfire behavior. Sci. Rep. 2020, 10, 17312. [CrossRef]

30. Aganetti, R.; Lamorlette, A.; Guilbert, E.; Morvan, D.; Thorpe, G. Advection and the self-heating of organic porous media. Int. J. Heat Mass Transf. 2016, 93, 1150-1158. [CrossRef]

31. Moinuddin, K.; Khan, N.; Sutherland, D. Numerical study on effect of relative humidity (and fuel moisture) on modes of grassfire propagation. Fire Saf. J. 2021, 125, 103422. [CrossRef]

32. Lamorlette, A.; El Houssami, M.; Morvan, D. An improved non-equilibrium model for the ignition of living fuel. Int. J. Wildland Fire 2018, 27, 29. [CrossRef]

33. Terrei, L.; Lamorlette, A.; Ganteaume, A. Modelling the fire propagation from the fuel bed to the lower canopy of ornamental species used in wildland-urban interfaces. Int. J. Wildland Fire 2019, 28, 113. [CrossRef]

34. Byram, G.M. Atmospheric Conditions Related to Blowup Fires; USDA-Forest Service, Southeastern Forest Experiment Station: Asheville, NC, USA, 1954. 
35. Noble, I.; Gill, A.; Bary, G. McArthur's fire-danger meters expressed as equations. Aust. J. Ecol. 1980, 5, 201-203. [CrossRef]

36. Sharples, J.J.; Mills, G.A.; McRae, R.H.D.; Weber, R.O. Fire danger anomalies associated with Foehn-like winds in southeastern Australia. In Proceedings of the 18th World IMAC/MODSIM Congress, Cairns, Australia, 13-17 July 2009.

37. Richards, P.; Norris, S. Appropriate boundary conditions for computational wind engineering models revisited. J. Wind Eng. Ind. Aerodyn. 2011, 99, 257-266. [CrossRef]

38. Byram, G.M. Combustion of forest fuels. In Forest Fire: Control and Use; Davis, K.P., Ed.; McGraw-Hill: New York, NY, USA, 1959; pp. 61-89.

39. Kremer, H.; Schäfer, G. Rates of fuel conversion and heat release in turbulent combustion of methane-air mixtures in tunnel burners. Symp. Int. Combust. 1973, 14, 707-717. [CrossRef]

40. Lund, T.S.; Wu, X.; Squires, K. Generation of Turbulent Inflow Data for Spatially-Developing Boundary Layer Simulations. J. Comput. Phys. 1998, 140, 233-258. [CrossRef]

41. Wu, X. Inflow Turbulence Generation Methods. Annu. Rev. Fluid Mech. 2017, 49, 23-49. [CrossRef]

42. Bonnet, J.-P.; Delville, J.; Lamballais, E. The Generation of Realistic 3D, Unsteady Inlet Conditions for LES. In Proceedings of the 41st Aerospace Sciences Meeting and Exhibit, Reno, NV, USA, 6-9 January 2003.

43. Davidson, L. Hybrid LES-RANS: Inlet boundary conditions for flows including recirculation. In Fifth International Symposium on Turbulence and Shear Flow Phenomena, Munich, Germany, 27-29 August 2007; Beell House Inc.: Munich, Germany, 2007.

44. Ghaderi, M.; Ghodrat, M.; Sharples, J. LES Simulation of Wind-Driven Wildfire Interaction with Idealized Structures in the Wildland-Urban Interface. Atmosphere 2020, 12, 21. [CrossRef]

45. Tominaga, Y.; Mochida, A.; Yoshie, R.; Kataoka, H.; Nozu, T.; Yoshikawa, M.; Shirasawa, T. AIJ guidelines for practical applications of CFD to pedestrian wind environment around buildings. J. Wind Eng. Ind. Aerodyn. 2008, 96, 1749-1761. [CrossRef]

46. Wang, Y.; Chatterjee, P.; de Ris, J.L. Large eddy simulation of fire plumes. Proc. Combust. Inst. 2011, 33, 2473-2480. [CrossRef]

47. Castro, I.P.; Robins, A.G. The flow around a surface-mounted cube in uniform and turbulent streams. J. Fluid Mech. 1977, 79, 307-335. [CrossRef]

48. Sikanen, T.; Hostikka, S. Modeling and simulation of liquid pool fires with in-depth radiation absorption and heat transfer. Fire Saf. J. 2016, 80, 95-109. [CrossRef]

49. Finney, M.A. The challenge of quantitative risk analysis for wildland fire. For. Ecol. Manag. 2005, 211, 97-108. [CrossRef]

50. Smith, S. The Performance of Distribution Utility Poles in Wildland Fire Hazard Areas; Technical Bulletin: Newport Beach, CA, USA, 2014.

51. Verma, M.K. Physics of Buoyant Flows: From Instabilities to Turbulence; World Scientific: Singapore, 2018.

52. Guo, Y.; Yuan, Z.; Yuan, Y.; Cao, X.; Zhao, P. Numerical simulation of smoke stratification in tunnel fires under longitudinal velocities. Undergr. Space 2020, 6, 163-172. [CrossRef]

53. Himoto, K.; Deguchi, Y. Temperature elevation and trajectory in the downwind region of rectangular fire sources in cross-winds. Fire Saf. J. 2020, 116, 103183. [CrossRef]

54. Wu, Y.; Xing, H.; Atkinson, G. Interaction of fire plume with inclined surface. Fire Saf. J. 2000, 35, 391-403. [CrossRef]

55. Debnam, G.; Chow, V. Construction of Buildings in Bushfire Prone Areas Draft for Public Comment Review of Calculation Methods and Assumptions, England, P. AS 3959. 2005. Available online: https:/ / www.semanticscholar.org/paper/AS-3959 -CONSTRUCTION-OF-BUILDINGS-IN-BUSHFIRE-PRONE-Debnam-England/bfaa33f997c5632b28a1692bc03c47e4095f1fc5 (accessed on 10 January 2022). 